\title{
Association between fractional exhaled nitric oxide, sputum induction and peripheral blood eosinophil in uncontrolled asthma
}

Jie Gao*i(i) and Feng Wu

\begin{abstract}
Background: The fractional exhaled nitric oxide (FeNO) and blood eosinophils are biomarkers of eosinophilic airway inflammation used in the diagnosis and management of asthma, although induced sputum is the gold standard test for phenotypic asthma. Nevertheless, the clinical application of the correlation between sputum eosinophils, FeNO and blood eosinophils is controversial.
\end{abstract}

Objective: To investigate the clinical application of the correlation between sputum eosinophils, FeNO and blood eosinophils with uncontrolled asthmatic patients. It also examined the relationships between these biomarkers in bronchial reversibility and bronchial hyper-responsiveness (BHR).

Methods: This study evaluated 75 uncontrolled asthmatic patients (symptom control and future risk of adverse outcomes). All patients underwent the following on the same day: FeNO, spirometry, BHR or bronchodilator reversibility, sputum induction and blood collection. Eosinophilic airway inflammation was defined as sputum eosinophils $\geq 2.5 \%$ or FeNO levels $\geq 32$ parts per billion (ppb).

Results: A significant positive relationship was between percentage of sputum eosinophils and FeNO $(r=0.4556$; $p<0.0001)$ and percentage of blood eosinophils ( $r=0.3647 ; p=0.0013)$, and a significant negative correlation was between percentage of sputum neutrophils and FeNO $(r=-0.3653 ; p=0.0013)$. No relationship between FeNO and percentage of blood eosinophils $(p=0.5801)$. ROC curve analysis identified FeNO was predictive of sputum eosinophilia [area under the curve (AUC) 0.707, $p=0.004$ ] at a cutoff point of $35.5 \mathrm{ppb}$ (sensitivity $=67.3 \%$, specificity $=73.9 \%$ ). Percentage of blood eosinophils was also highly predictive with an AUC of $0.73(p=0.002)$ at a cut-off point of $1.5 \%$, sensitivity and specificity were 61.5 and $78.3 \%$, respectively. Although the sputum neutrophil percentage was correlated with FeNO, ROC curve of these parameters did not show useful values (AUC $=0.297, p=0.003$; $A \cup C=0.295, p=0.021$.

Conclusions and clinical relevance: Blood eosinophils and FeNO can accurately predict eosinophilic airway inflammation in uncontrolled asthmatic patients. FeNO is poor surrogates for sputum neutrophils and blood eosinophils. The FeNO level and blood eosinophils, which determine an optimal cutoff for sputum eosinophilia, need more studies.

Keywords: Asthma, Sputum, FeNO, Blood, Eosinophil, Neutrophil, BHR, Bronchial reversibility

\footnotetext{
${ }^{*}$ Correspondence: xiekewei-568@126.com

Department of Respiratory Medicine, The Third People's Hospital,

Guangzhou Medical College, 1\# Xuebei Ave., Huizhou 516002,

Guangdong, China
}

(c) The Author(s) 2018. This article is distributed under the terms of the Creative Commons Attribution 4.0 International License (http://creativecommons.org/licenses/by/4.0/), which permits unrestricted use, distribution, and reproduction in any medium, provided you give appropriate credit to the original author(s) and the source, provide a link to the Creative Commons license, and indicate if changes were made. The Creative Commons Public Domain Dedication waiver (http://creativecommons.org/ publicdomain/zero/1.0/) applies to the data made available in this article, unless otherwise stated. 


\section{Background}

Asthma is a heterogeneous disease, characterized by the history of variable respiratory symptoms such as wheeze, shortness of breath, chest tightness and cough, usually together with variable expiratory airflow limitation. This was reached by consensus, recommended by the 2017 Global Initiative for Asthma (GINA) [1]. It has been recognized that among asthmatic patients there are clusters of demographic, clinical and/or pathophysiological characteristics, which has been called "asthma phenotypes" $[1,2]$. However, to date, no strong relationship has been found between specific pathological features and particular clinical or treatment responses [3]. When examining the airway inflammation using sputum analysis, patients with asthma can be classified in four different inflammatory phenotypes. Based on the percentage of eosinophils and neutrophils in sputum, it was to define four airway inflammatory subgroups: eosinophilic asthma, neutrophilic asthma, mixed granulocytic asthma and paucigranulocytic asthma [4]. There is recent evidence from prospective clinical studies that airway inflammatory phenotype can help to optimise therapy and disease outcome. Eosinophilic asthma responds well to antiinflammatory treatment with steroids, non-eosinophilic asthma shows little or no response [5]. This suggests that biomarkers of inflammation could be considered in identifying and monitoring of asthmatic patients in clinical practice, such as the titration of steroid treatment.

Airway inflammatory phenotype can be measured through the airway noninvasively by induced sputum analysis $[2,4]$ and fractional exhaled nitric oxide (FeNO) [6]. Both are considered as a direct, reliable, sensitive, simple, and repeatable method of assessing inflammatory phenotypes, widely used in clinical practice. Peripheral blood eosinophils has also been studied as another potentially biomarker; it is associated with the patient's future risk for exacerbations $[7,8]$, the risk factor for developing fixed airflow limitation [9], the diagnosis of eosinophilic asthma [10]. In 2016, the normal reference values of induced sputum cytology in China, defined as sputum eosinophils $\geq 2.5 \%$, and increases in FeNO level $\geq 32 \mathrm{ppb}$, were identified as airway eosinophilia [11]. Nevertheless, the clinical application of the correlation between FeNO levels, sputum eosinophils and peripheral blood eosinophils is controversial.

We conducted a retrospective study to (1) evaluate the correlation between sputum eosinophils, FeNO level and peripheral blood eosinophils in patients with asthma (2) to determine the accuracy of these biomarkers as indicators of airway inflammatory phenotypes in these patients (3) assess the relationship between these biomarkers, bronchial hyper-responsiveness (BHR) and bronchodilator reversibility in asthma.

\section{Methods}

\section{Study design and participants}

We conducted a retrospective study on a series of 65 patients with asthma visiting in The Third People's Hospital of Guangzhou Medical College in Huizhou from April 2016 to June 2017. Asthma patients were diagnosed according to a clinical history of wheezing, cough, chest tightness or shortness of breath, as well as the presence of bronchial hyper-responsiveness or bronchodilator reversibility, based on the 2016 of the Chinese national Guidelines on Diagnosis and Management of Asthma [12]. Included asthma patients received initial diagnosis and were uncontrolled stage. The level of asthma control was defined by asthma symptoms control (in the past 4 weeks, has the patient had daytime asthma symptoms more than twice/week and/or any night waking due to asthma and/or any activity limitation due to asthma and/ or reliever needed for symptoms' more than twice/week) and future risk of adverse outcomes (in the past 4 weeks, has the patient had $\mathrm{FEV}_{1} \%$ less than normal predicated value and/or any severe exacerbation due to asthma). Uncontrolled asthmatic patient had equal to or greater than 3 features as the above.

Inclusion criteria were any patients with asthma aged $\geq 18$ years who agreed to undergo detailed investigation. All the patients who had successful FeNO, lung function and sputum induction were included in the study. Data were collected during regular clinical practice and medical procedures. Their demographic and functional characteristics are summarized in Tables 1,2 and 3.

Exclusion criteria were any patients had a history with chronic obstructive pulmonary disease (COPD), or previous doctor-diagnosed asthma-COPD overlap [(ACO),

Table 1 Patient demographics and baseline characteristics

\begin{tabular}{ll}
\hline Demographic parameter & $\begin{array}{l}\text { All participants } \\
(\mathbf{N}=\mathbf{7 5})\end{array}$ \\
\hline Age, years, median & $61(53,71)$ \\
Range & $18-85$ \\
Males, $\mathrm{n}(\%)$ & $42(56)$ \\
Race, $\mathrm{n}(\%)$ & \\
Chinese & $75(100 \%)$ \\
Mean height, $\mathrm{cm}(\mathrm{SD})$ & $160(8.78)$ \\
Range & $136-174$ \\
Mean weight, $\mathrm{kg}(\mathrm{SD})$ & $59(9.29)$ \\
Range & $44.5-84$ \\
Mean body mass index, $\mathrm{kg} / \mathrm{m}^{2}$ (SD) & $23.2(3.61)$ \\
Range & $16.71-34.22$ \\
Smokers, $\mathrm{n}(\%)$ & $32(42.7)$
\end{tabular}

$\mathrm{N}$, total population; $\mathrm{n}$, sub-group population; $\mathrm{SD}$, standard deviation 
Table 2 Spirometry results for the patients

\begin{tabular}{lc}
\hline Variable & $\begin{array}{l}\text { All participants } \\
(\mathbf{N}=\mathbf{7 5})\end{array}$ \\
\hline FVC (L), mean (SD) & $2.94(0.86)$ \\
FVC\% predicted, mean (SD) & $97.03(13.96)$ \\
FEV1 (L), mean (SD) & $1.99(0.57)$ \\
FEV1\% predicted, mean (SD) & $81.77(11.86)$ \\
FEV1/FVC (\%), mean (SD) & $68.33(8.54)$ \\
PEF (L/min), mean (SD) & $5.33(1.76)$ \\
PEF\% predicted, mean (SD) & $78.45(17.64)$ \\
MMEF, mean (SD) & $1.36(0.5)$ \\
MMEF\% predicted, mean (SD) & $40.46(18.25)$ \\
MEF50\% (L/s), mean (SD) & $1.76(0.76)$ \\
MEF50\% predicted, mean (SD) & $47.55(20.86)$ \\
MEF25\% (L/s), mean (SD) & $0.59(0.26)$ \\
MEF25\% predicted, mean (SD) & $45.34(19.62)$
\end{tabular}

FVC, forced vital capacity; FEV1, forced expiratory volume in $1 \mathrm{~s}$; PEF, peak expiratory flow; MMEF, maximum mid-expiratory flow; MEF, maximal expiratory flow

Table 3 FeNO level, induced sputum and peripheral blood result for the patients

\begin{tabular}{lc}
\hline Variable & $\begin{array}{c}\text { All participants } \\
(\mathbf{N}=\mathbf{7 5})\end{array}$ \\
\hline FeNO level, ppb & $38(20,72)$ \\
Eosinophil (\%) in sputum & $4.2(1.1,15.7)$ \\
Neutrophil (\%) in sputum, mean (SD) & $78.51(17.3)$ \\
White blood cell $\left(\times 10^{9} / \mathrm{L}\right)$ & $7.6(6.4,9.9)$ \\
Eosinophil $(\%)$ in peripheral blood & $0.1(0,0.3)$ \\
Eosinophil count in peripheral blood $\left(\times 10^{9} / \mathrm{L}\right)$ & $1.4(0.4,3.2)$ \\
\hline
\end{tabular}

Values are expressed as median (inter quartile range) or mean (SD)

COPD/ACO was distinguished according to the 2017 recommendation of GINA, on the basis of chronic respiratory symptoms and post-bronchodilator $\mathrm{FEV}_{1} / \mathrm{FVC}<0.7$ or $\mathrm{FEV}_{1} / \mathrm{FVC}<0.7$ after treatment]. Patients have used any oral or/and inhaled corticosteroid in the previous 12 weeks. Patients had a confounding pulmonary comorbidity such as a pulmonary tuberculosis, an interstitial lung disease, a lung cancer or a pulmonary infection. Patients had a cognitive impairment that may affect the collaboration or comprehension of the study.

\section{Ethics statement}

The Institutional Review Board of the Third People's Hospital of Guangzhou Medical College in Huizhou approved the study protocol and absolved the need for written informed consent from patients as the study was a retrospective study, personal identification data were anonymized.

\section{Assessments and study procedures}

On the same day the following tests or determinations were performed: FeNO test, pulmonary function test (PFT), BHR test or bronchodilator reversibility test, induced sputum and routine blood test. Clinical variables were recorded for the participants.

FeNO: FeNO level was measured before PFT according to the guidelines in the user manual training on the NO electrochemical equipment (NIOX VERO; Aerocrine AB, Solna, Sweden). Patients were required to refrain from eating, drinking, and smoking for at least $1 \mathrm{~h}$ prior to the FeNO measurement. Patients were instructed to inhale NO-free air to total lung capacity and immediately exhale fully into the device at a sustained flow rate of $50 \mathrm{~mL} / \mathrm{s}$ for 6 or $10 \mathrm{~s}$, which resulted in display of FeNO value 6 . A significant increase in FeNO was considered if the FeNO value was equal to or higher than 32 parts per billion (ppb) [6].

PFT: Airway limitation was identified using lung function machine (MS-pneumo+aps; Jaeger, Friedberg, German) by an experienced technician according to the 2014 recommendations of the Chinese National Guidelines of Pulmonary Function Test. Percentage predicted values (\%pred) were calculated based on reference values for healthy Chinese adults. All patients were required to undergo PFT in a reproducible way, and the best values were retained [13].

BHR test: PFT values were assessed prior to the methacholine challenge. Patients with a FEV1\%pred $<60 \%$ were excluded from the BHR test (at baseline). The breath dosimeter method was used according to published guidelines from Chinese National Guidelines of Pulmonary Function Test. The test sequence included five steps: $0.9 \% \mathrm{NaCl}$ only, $0.078,0.312,1.125$ and $2.504 \mathrm{mg}$. Measure the $\mathrm{FEV}_{1}$ at about $60 \mathrm{~s}$ from the start of one to the start on the next inhalation from the nebulizer. Obtain an acceptable-quality FEV1 at each time point. Airway responsiveness was required to induce a $20 \%$ decrease in FEV1 $\left(\mathrm{PD}_{20}\right)$, and the positive response was defined as $\mathrm{PD}_{20} \leq 2.504 \mathrm{mg}$ (between NS and 2.504 mg) [13].

Bronchodilator reversibility test: Patients were asked to inhale $400 \mu \mathrm{g}$ salbutamol via a metered-dose inhaler after baseline evaluation, and PFT was repeated not less than $20 \mathrm{~min}$. Three forced expiratory maneuvers were recorded. The positive response, which was defined as $\mathrm{FEV}_{1}>12 \%$ and $200 \mathrm{~mL}$ after salbutamol inhalation, were obtained [13].

Sputum induction: Sputum was induced with hypertonic saline inhalation through ultrasonic atomizer. A single hypertonic saline $(3 \% \mathrm{NaCl})$ was used. Patients were asked to inhale $400 \mu \mathrm{g}$ salbutamol via a metereddose inhaler $20 \mathrm{~min}$ before induction. Collected lower respiratory sputum portions of induced sputum were 
dispersed using $0.1 \%$ dithiothreitol in a water bath $\left(37^{\circ} \mathrm{C}\right)$ and oscillator $15 \mathrm{~min}$ before the 300 mesh nylon mesh filter. Subsequently, total cell count was centrifuged, smeared and stained (hematoxylin-eosin). A differential cell count was obtained from 400 cells under $400 \times$ microscope to identify the type of airway inflammation in patients with asthma. We defined percentage of sputum eosinophils $\geq 2.5 \%$ as abnormal [11].

Blood collection and analysis: Peripheral venous blood was measured using Automated Hematology Blood Analyzer (ABX Pentra DF120-1; ABX, France). The results of peripheral blood eosinophil percentage and absolute eosinophil count were obtained.

\section{Statistical analysis}

Analysis of the data was performed using SPSS 19 (IBM Corporation, Armonk, NY, USA). Continuous variables are expressed as mean $\pm \mathrm{SD}$ or median (interquartile range) for non-normal variables when appropriate, and categorical variables with the Chi square test. Non-normally distributed variables used the Mann-Whitney test. The relationship between FeNO, sputum eosinophils, blood eosinophils, BHR and bronchodilator reversibility was assessed using the Spearman's rank correlation coefficient. Correlation between tests was performed by constructing receiver operating characteristic (ROC) curve. The optimal cutoff value was determined from the highest sum of sensitivity and specificity. Statistical significance was defined as $\mathrm{p}<0.05$.

\section{Results}

\section{Characteristics of the patients}

Patient demographic information is presented in Table 1. A total of 75 patients with uncontrolled asthma participated [42 (56\%) males] in the study. The median age was 61 years with a range between 18 and 85 years. Smokers accounted for $42.7 \%$ of patients. All participants were Chinese. PFT results are reported in Table 2. Patients with uncontrolled asthma had a mean FEV1/ FVC\% of $68.33 \%$ and a mean FEV1\%pred of $81.77 \%$. The result of FeNO level, induced sputum and peripheral blood are reported in Table 3.

\section{Sputum induction}

Eosinophilic airway inflammation (sputum eosinophilia $\geq 2.5 \%$ ) was present in 52 participants. The characteristics of patients are shown in Table 4. Patients in sputum eosinophilia group compared with patients in sputum noneosinophilia group showed a significantly higher FeNO level $(p=0.011)$, in peripheral blood eosinophil percentage $(\mathrm{p}=0.003)$ and absolute eosinophil count $(\mathrm{p}=0.016)$.

\section{FeNO}

FeNO level equal to or higher than $32 \mathrm{ppb}$ was present in 45 participants. The characteristics of patients are shown in Table 5. Patients in the two groups showed a meaningless result in eosinophilic cell in peripheral blood percentage and absolute count, but a significantly increased in the percentage of sputum eosinophils $(\mathrm{p}<0.001)$.

\section{Peripheral blood eosinophils}

Eosinophilic percentage in peripheral blood $\geq 2 \%$ was present in 28 participants. The characteristics of patients are shown in Table 6 . The percentage of sputum eosinophils $(\mathrm{p}=0.001)$ and blood absolute eosinophil count $(p<0.001)$ were significantly higher in blood eosinophilia

Table 4 FeNO levels and peripheral blood result for the patients

\begin{tabular}{lccc}
\hline Variables & $\begin{array}{l}\text { Sputum eosinophilia } \\
(\mathbf{n}=\mathbf{5 2})\end{array}$ & $\begin{array}{l}\text { Sputum noneosinophilia } \\
(\mathbf{n}=\mathbf{2 3})\end{array}$ & p-value \\
\hline Age, years & $58(50,66)$ & $64(59,76)$ & 0.224 \\
Males, $\mathrm{n}(\%)$ & $30(57.7)$ & $12(52.2)$ & 0.657 \\
Mean body mass index, $\mathrm{kg} / \mathrm{m}^{2}$ & $23.3(3.86)$ & $22.98(3.03)$ & $9(39.1)$ \\
Smokers, $\mathrm{n}(\%)$ & $23(44.2)$ & $84.7(17.02)$ & 0.476 \\
Postbronchodilator FEV1\% predicted & $80.48(8.57)$ & $1.81(0.51)$ & 0.68 \\
Postbronchodilator FEV 1 (L) & $2.06(0.58)$ & $68.82(7.7)$ & 0.07 \\
Postbronchodilator FEV $/$ FVC (\%) & $68.12(8.95)$ & $24(19,47)$ & $0.57 .7(10.55)$ \\
FeNO level (ppb) & $48(25,92)$ & $8.5(6.5,10.3)$ & 0.297 \\
Neutrophil (\%) in sputum & $74.36(18.11)$ & $0.5(0.2,1.8)$ & 0.011 \\
White blood cell $\left(\times 10^{9} / \mathrm{L}\right)$ & $7.3(6.2,9.6)$ & $0(0,0.2)$ & 0.062 \\
Eosinophil $(\%)$ in peripheral blood & $1.8(0.6,4.8)$ & 0.192 \\
Eosinophil count in peripheral blood $\left(\times 10^{9} / \mathrm{L}\right)$ & $0.1(0.1,0.3)$ & 0.003
\end{tabular}


Table 5 Sputum induction and peripheral blood result for the patients

\begin{tabular}{|c|c|c|c|}
\hline Variables & $\begin{array}{l}\text { FeNO } \geq 32 \mathrm{ppb} \\
(\mathrm{n}=45)\end{array}$ & $\begin{array}{l}\text { FeNO }<32 \mathrm{ppb} \\
(\mathrm{n}=30)\end{array}$ & p-value \\
\hline Age, years & $58(49,65.5)$ & $63.5(58.5,75.3)$ & 0.386 \\
\hline Males, n (\%) & $26(57.8)$ & $16(53.3)$ & 0.704 \\
\hline Mean body mass index, $\mathrm{kg} / \mathrm{m}^{2}$ & $22.62(3.35)$ & $24.07(3.86)$ & 0.396 \\
\hline Smokers, n (\%) & $21(46.7)$ & $11(36.7)$ & 0.391 \\
\hline Postbronchodilator FEV1\% predicted & $82.38(12.68)$ & $80.86(10.64)$ & 0.71 \\
\hline Postbronchodilator FEV1 (L) & $2.12(0.56)$ & $1.78(0.52)$ & 0.875 \\
\hline Postbronchodilator FEV1/FVC (\%) & $68.22(8.7)$ & $68.5(8.44)$ & 0.953 \\
\hline Eosinophil (\%) in sputum & $9.89(3.65,20.53)$ & $2.44(0.59,4.05)$ & $<0.001$ \\
\hline Neutrophil (\%) in sputum, mean (SD) & $74.15(18.56)$ & $84.9(12.83)$ & 0.076 \\
\hline White blood cell $(\times 109 / L)$ & $7.6(6.3,10.3)$ & $7.5(6.4,9.6)$ & 0.841 \\
\hline Eosinophil (\%) in peripheral blood & $1.8(0.3,4.8)$ & $1.3(0.5,2.93)$ & 0.97 \\
\hline Eosinophil count in peripheral blood $(\times 109 / L)$ & $0.1(0,0.3)$ & $0.1(0.08,0.23)$ & 0.889 \\
\hline
\end{tabular}

Significant $p$ value $<0.05$

Table 6 FeNO level and sputum induction result for the patients

\begin{tabular}{lccc}
\hline Variables & $\begin{array}{l}\text { Blood eosinophilia } \\
(\mathbf{n = 2 8 )}\end{array}$ & $\begin{array}{l}\text { Blood noneosinophilia } \\
(\mathbf{n = 4 7 )}\end{array}$ & p-value \\
\hline Mean age, years & $58(52.3,71.3)$ & $62(53,71)$ & 0.496 \\
Males, $\mathrm{n}(\%)$ & $16(57.1)$ & $26(55.3)$ & 0.878 \\
Mean body mass index, $\mathrm{kg} / \mathrm{m}^{2}$ & $22.64(3.15)$ & $23.54(3.85)$ & 0.509 \\
Smokers, $\mathrm{n}(\%)$ & $11(39.3)$ & $21(44.7)$ & 0.648 \\
Postbronchodilator FEV1\% predicted & $83.29(7.33)$ & $80.87(13.87)$ & 0.23 \\
Postbronchodilator FEV1 (L) & $2.13(0.59)$ & $6.9(0.54)$ & 0.696 \\
Postbronchodilator FEV1/FVC (\%) & $68.32(8.02)$ & $35(19,65)$ & 0.505 \\
FeNO level, (ppb) & $48(25,95)$ & $3.6(0.5,10.3)$ & 0.103 \\
Eosinophil (\%) in sputum & $9.85(3.52,24.83)$ & $82.66(14.51)$ & 0.001 \\
Neutrophil (\%) in sputum, mean (SD) & $71.37(19.34)$ & $7.9(6.8,10.3)$ & 0.151 \\
White blood cell $\left(\times 10^{9} / \mathrm{L}\right)$ & $6.9(6,9.2)$ & $0.1(0,0.1)$ & 0.069 \\
Eosinophil count in peripheral blood $\left(\times 10^{9} / \mathrm{L}\right)$ & $0.3(0.2,0.7)$ & $<0.001$ \\
\hline
\end{tabular}

Blood eosinophilia refers to peripheral blood eosinophils $\geq 2 \%$; blood noneosinophilia refers to peripheral blood eosinophils $<2 \%$. Significant $\mathrm{p}$ value $<0.05$

group. Nonetheless, FeNO level was not different between groups.

\section{Associations between FeNO level, sputum induction, peripheral blood eosinophils, BHR and bronchodilator reversibility}

A significant positive relationship was observed between percentage of sputum eosinophils and FeNO level $(\mathrm{r}=0.4556 ; \mathrm{p}<0.0001)$ (Fig. 1a) and percentage of blood eosinophils $(r=0.3647 ; p=0.0013)$ (Fig. $1 b)$, and a significant negative correlation between percentage of sputum neutrophils and FeNO level $(\mathrm{r}=-0.3653 ; \mathrm{p}=0.0013)$ (Fig. 1c). We also found weaker but significant correlations between percentage of sputum neutrophils and percentage of blood eosinophils $(r=-0.2294 ; \mathrm{p}=0.0477)$
(Fig. 1d). No relationship between FeNO level and percentage of blood eosinophils $(\mathrm{p}=0.5801)$.

Evidence of variable airflow obstruction was observed in 75 participants, 44 of whom had airway hyper-responsiveness based on the methacholine challenge results, and 31 had bronchodilator reversibility. There were no significant relationship between PD20 and percentage of sputum eosinophils $(p=0.2505)$, PD20 and FeNO level $(\mathrm{p}=0.0955)$, PD20 and blood eosinophil percentage/count $(\mathrm{p}=0.4517 ; \mathrm{p}=0.4933$; respectively). There were also no significant relationship between $\triangle \mathrm{FEV} 1(\Delta$, improvement in FEV1 after $400 \mu \mathrm{g}$ of salbutamol) and percentage of sputum eosinophils $(p=0.3645)$. Neither FeNO level $(\mathrm{p}=0.281)$ nor blood eosinophil percentage/ 

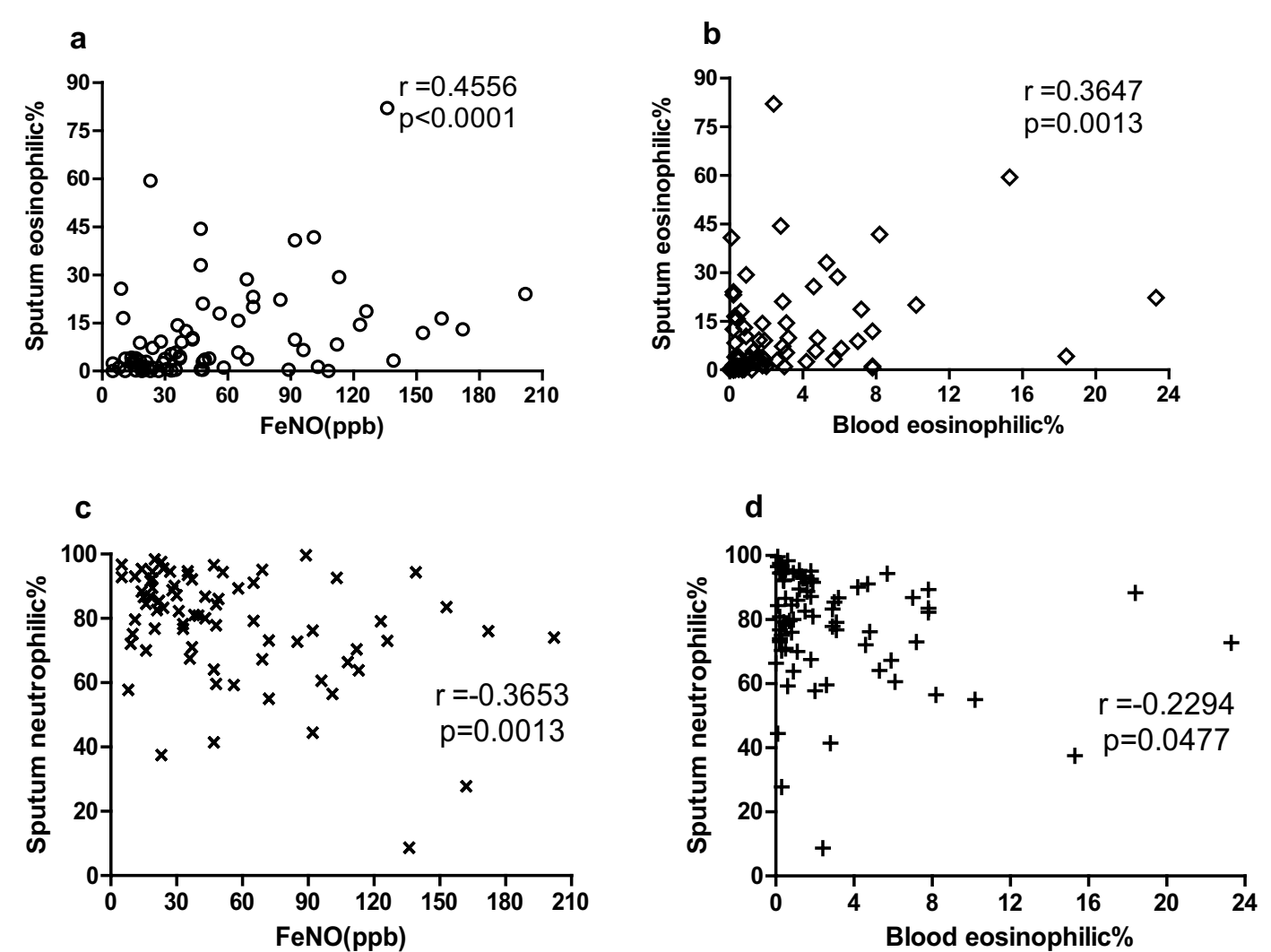

Fig. 1 Scatter plots of correlation between sputum eosinophil/neutrophil percentage, FeNO level and peripheral blood eosinophil percentage. a Correlation between sputum eosinophil percentage and FeNO level. b Correlation between sputum eosinophil percentage and blood eosinophil percentage. c Correlation between sputum neutrophil percentage and FeNO level. d Correlation between sputum neutrophil percentage and blood eosinophil percentage

count $(\mathrm{p}=0.6027 ; \mathrm{p}=0.1236$; respectively) did not correlate with bronchodilator reversibility.

The ROC curve analysis identified FeNO level as the best predictor for sputum eosinophilia with an area under the curve (AUC) of $0.707(\mathrm{p}=0.004)$. The optimum cut-point for FeNO level was $35.5 \mathrm{ppb}$, and this yielded a sensitivity of $67.3 \%$, a specificity of $73.9 \%$. The percentage of blood eosinophils was also highly predictive with an area under the curve of $0.73(\mathrm{p}=0.002)$ at a blood eosinophils cut-off of $1.5 \%$, sensitivity and specificity were 61.5 and $78.3 \%$, respectively (Fig. 2a). In addition, $4.36 \%$ was the best diagnostic cut-off value of percentage of sputum eosinophils for $32 \mathrm{ppb}$ of FeNO level, with an ROC AUC of $0.755(\mathrm{p}<0.001)$, sensitivity and specificity were 68.9 and $80 \%$, respectively (Fig. 2b). Although the sputum neutrophil percentage was correlated with FeNO level, a ROC curve of these parameters did not show useful values (AUC $=0.297, p=0.003$, Fig. $2 b ; A U C=0.295$, $\mathrm{p}=0.021$, Fig. 2c). Percentage of blood eosinophils $(\mathrm{p}=0.97)$ failed in the correlation of FeNO level.
There was no difference between blood eosinophil percentage $(p=0.089)$ and absolute blood eosinophil count $(\mathrm{p}=0.14)$ in the prediction of sputum neutrophilia.

\section{Discussion}

This study assessed the correlation of FeNO level, sputum eosinophils and blood eosinophils in initial diagnosis and uncontrolled asthma. All the people in the study were Chinese. FeNO level and percentage of blood eosinophils can accurately predict sputum eosinophilia. Percentage of sputum neutrophils was correlated with FeNO level and percentage of blood eosinophils, but not enough to be clinically useful. We also identified some additional findings, namely $\mathrm{PD}_{20} / \Delta \mathrm{FEV}_{1}$ association with FeNO level and percentage of sputum/blood eosinophils, which may reflect nothing.

There is a need to include simple and accessible biomarkers in the management of asthmatic airway inflammatory subtype, FeNO and blood eosinophils are markers of local and systemic eosinophilic inflammation, respectively. According to the literature, biomarkers of airway eosinophilic inflammation (FeNO, blood 

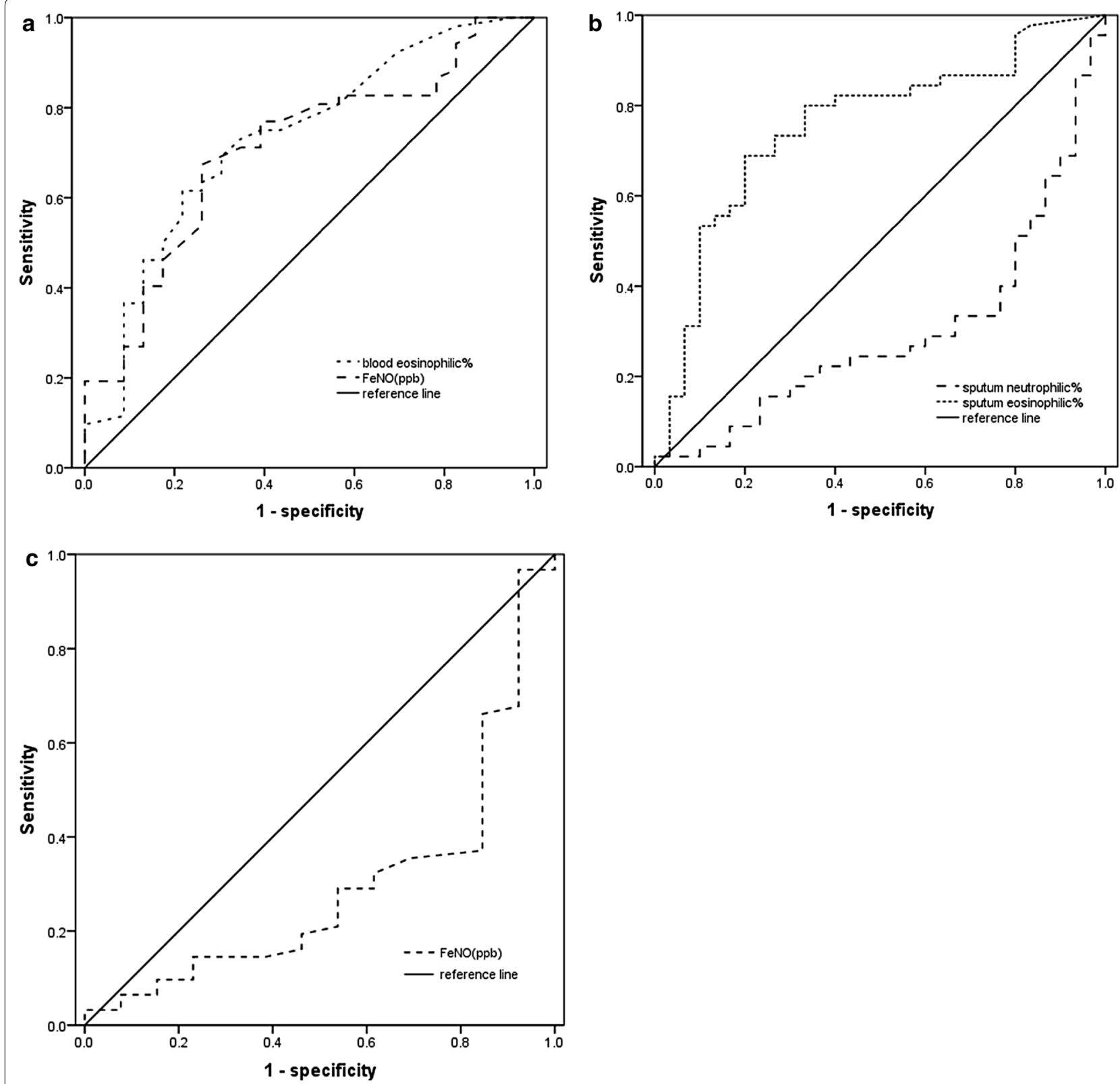

Fig. 2 ROC curve for FeNO level and blood eosinophil percentage to predict sputum eosinophilia ( $\geq 2.5 \%)$ (a), ROC curve for sputum eosinophil/ neutrophil percentage to predict FeNO level ( $\geq 32 \mathrm{ppb})(\mathbf{b})$, ROC curve for FeNO level to predict sputum neutrophilia ( $\geq 65 \%)(\mathbf{c})$

eosinophils and others, such as the sputum eosinophils) are well correlated with each other [14-16]. However, there is disagreement in the literature as to the value of FeNO level and sputum/blood eosinophils and there is no study following the diagnostic criteria of China [17, 18]. Few studies have used ROC to assess the ability of FeNO and peripheral blood eosinophils to detect airway eosinophilic phenotypes. Our results resolve these issues by showing that FeNO level and peripheral blood eosinophils were an excellent predictor of sputum eosinophilia in the clinically important subgroup of patients who received initial diagnosis and were uncontrolled asthma.

Following the 2016 recommendations of the Chinese National Guidelines on Diagnosis and Management of Cough, eosinophilic airway inflammation was defined as percentage of eosinophils $\geq 2.5 \%$ in induced sputum [11]. As shown in Table 4, FeNO level and peripheral blood eosinophils percentage/count were different. Although induced sputum has been considered the "gold standard" for airway inflammatory phenotypes, measurement of 
FeNO has achieved wide acceptance in routine clinical practice because it is easy to perform and readily available readout. The 2016 recommendation also suggested that a significant increase in sputum eosinophils $\geq 2.5 \%$ was considered if the FeNO level was $\geq 32 \mathrm{ppb}$ [11]. As shown in Table 5, the percentage of sputum eosinophils was significantly different; however, the difference in peripheral blood eosinophil percentage and absolute count were not significant. According to the 2017 recommendation of GINA, which recently published an evidence-based clinical research guideline, eosinophil, such as in induced sputum or peripheral venous blood, can predict the risk of exacerbations [1]. We predicted that sputum eosinophilia was considered if the peripheral blood eosinophil percentage was $\geq 2 \%$. As shown in Table 6, percentage of sputum eosinophils was different; however, the difference between FeNO in the two groups was not significant.

In clinical practice, there is a tendency to generalize the correlation between FeNO and percentage of sputum eosinophils, although the two methods are useful to assess the eosinophilic airway inflammation [19-21]. Our present optimal cutoff point $(35.5 \mathrm{ppb})$ is similar to this optimal cut-off point (32 ppb) in the 2015 recommendation of China. These results showed that FeNO was to distinguish the patients with uncontrolled asthma with sputum eosinophilia from those without, thereby indicating its potential use as a diagnostic biomarker for eosinophilic asthma. However, there are confounding factors that may affect FeNO values in many cases. As a nitraterich diet or the contamination of nasal NO increase, and smoking or spirometry decrease FeNO, these factors should be avoided or taken into account when measuring FeNO [6]. The cutoff value has been a question in dispute because normal or low FeNO levels do not exclude the presence of disease. Optimal cutoff points by calculating sensitivity and specificity on an ROC curve to assess diagnostic biomarkers of eosinophilic airway inflammation may not be clinically applicable, given that their sensitivity and/or specificity is often suboptimal compared to that of reference standard tests [22]. Furthermore, FeNO has a limited value to assess the sputum neutrophilia, our study provided that sputum neutrophil percentage was correlated with FeNO level, a ROC curve of these parameters did not show useful values $(\mathrm{AUC}=0.297, \mathrm{p}=0.003$; $\mathrm{AUC}=0.295, \mathrm{p}=0.021$ ). Bronchial induced sputum cytology provides a more accurate approximation of airway inflammation phenotypes in asthma patients than FeNO.

The 2017 GINA recently published an evidence-based clinical research guideline that blood eosinophils may be a biomarker of exacerbation risk in patients with a history of exacerbation and can predict the effects of ICS on exacerbation prevention [1]. Because of their accuracy and convenience, blood eosinophils can be used in the clinic for detecting airway eosinophilia in uncontrolled asthma. One study in uncontrolled asthma has shown that peripheral blood eosinophil percentage $(2.7 \%)$ and absolute count $\left(0.26 \times 10^{9} / \mathrm{L}\right)$ can serve as a diagnostic biomarker of sputum eosinophilia ( $\geq 3 \%$ ) (AUC 0.907, sensitivity $=92.2 \%$, specificity $=75.8 \%$; AUC 0.898 , sensitivity $=83.1 \%$, specificity $=82.8 \%$, respectively) [10]. These finding also indicates that percentage of blood eosinophils has a higher relevance than FeNO with eosinophil sputum in patients with asthma. These results suggest that blood eosinophils can be useful in assessing eosinophilic asthma and may have a role in selecting add-on therapy. However, there was no correlation between FeNO level and blood eosinophil percentage/count $(\mathrm{p}=0.5801)$ in our study.

\section{Limitations and future research}

One limitation of the study was that the p-value $(\mathrm{p}=0.0477)$ changed slightly under 0.05 , and the correlation coefficients $(r=-0.2294)$ were very low, as shown in Fig. 1d. The given number of data points may not be taken as strong evidence for such a relationship. It is possible that no relevant correlation between sputum neutrophil percentage and blood eosinophil percentage exists in the clinical practice.

The other was smoking cigarette factor. It is well known that smoking decreases FENO level [23]. Furthermore, some studies of the general population have reported that smoking increase blood eosinophils [24-26]. Other studies have reported blood eosinophils seems to be lower in asthmatic smokers than in asthmatic non-smokers [20, 27-29], and one study indicated that FeNO and blood eosinophils were significantly correlated in patients who have never smoked and former smokers but not in current smokers. There is disagreement in the literature as to the value of blood eosinophils [30]. Further investigation of smoking or no smoking factor in asthma would also benefit from bigger sample sizes.

\section{Conclusion}

This study provides that inflammatory biomarkers, including sputum eosinophils, FeNO level and blood eosinophils, can accurately predict sputum eosinophilia in patients with uncontrolled asthma. It suggests that peripheral blood eosinophil is a useful tool better than FeNO level for monitoring sputum eosinophilia in uncontrolled asthma. FeNO level is poor surrogates for sputum neutrophils and blood eosinophils. These data may be useful for identifying patients with eosinophilic airway inflammation who will have a beneficial response to treatment with an ICS, and it is important to help guide treatment and management of asthmatic patients. 


\section{Abbreviations}

FeNO: fractional exhaled nitric oxide; BHR: bronchial hyper-responsiveness: GINA: the Global Initiative for Asthma; FVC: forced vital capacity; FEV1: forced expiratory volume in $1 \mathrm{~s}$; PEF: peak expiratory flow; MMEF: maximum midexpiratory flow; MEF: maximal expiratory flow.

\section{Authors' contributions}

GJ performed data collection and analysis, and was a major contributor in writing the manuscript. WF analyzed and interpreted the patient data with asthma. Both authors read and approved the final manuscript.

\section{Acknowledgements}

The study was supported by Health and Family Planning Commission of Guangdong, People's Republic of China (grant ID: A2017535).

\section{Competing interests}

The authors declare that they have no competing interests.

\section{Availability of data and materials}

The datasets used and/or analysed during the current study are available from the corresponding author on reasonable request.

\section{Consent for publication}

Not applicable.

\section{Ethics approval and consent to participate}

The Institutional Review Board of The Third People's Hospital of Guangzhou Medical College in Huizhou approved the study protocol and absolved the need for written informed consent from patients as the study was retrospective study with personal identification data anonymized.

\section{Funding}

Not applicable.

\section{Publisher's Note}

Springer Nature remains neutral with regard to jurisdictional claims in published maps and institutional affiliations.

Received: 24 November 2017 Accepted: 2 April 2018

Published online: 23 May 2018

\section{References}

1. Global Initiative for Asthma. Global strategy for asthma management and prevention. http://ginasthma.org/2017-pocket-guide-for-asthmamanagement-andprevention/. Accessed 19 Jan 2017.

2. Bel EH. Clinical phenotypes of asthma. Curr Opin Pulm Med. 2004; 10:44-50

3. Anderson GP. Endotyping asthma: new insights into key pathogenic mechanisms in a complex, heterogeneous disease. Lancet. 2008;372:1107-19.

4. Simpson JL, Scott R, Boyle MJ, Gibson PG. Inflammatory subtypes in asthma: assessment and identification using induced sputum. Respirology. 2006;11:54-61.

5. Petsky HL, Cates CJ, Lasserson TJ, et al. A systematic review and metaanalysis: tailoring asthma treatment on eosinophilic markers (exhaled nitric oxide or sputum eosinophils). Thorax. 2012;67:199-208.

6. Dweik RA, Boggs PB, Erzurum SC, et al. An official ATS clinical practice guideline: interpretation of exhaled nitric oxide levels (FENO) for clinical applications. Am J Respir Crit Care Med. 2011;184:602-15.

7. Belda J, Giner J, Casan P, Sanchis J. Mild exacerbations and eosinophilic inflammation in patients with stable, well-controlled asthma after 1 year of follow-up. Chest. 2001;119(4):1011-7.

8. Ulrik CS. Peripheral eosinophil counts as a marker of disease activity in intrinsic and extrinsic asthma. Clin Exp Allergy. 1995;25(9):820-7.

9. Ulrik CS. Outcome of asthma: longitudinal changes in lung function. Eur Respir J. 1999:13:904-18.
10. Zhang $X Y$, Simpson JL, Powell H, et al. Full blood count parameters for the detection of asthma inflammatory phenotypes. Clin Exp Allergy. 2014:44:1137-45.

11. Asthma Workgroup of Chinese Society of Respiratory Diseases (CSRD), Chinese Medical Association. The Chinese national guidelines on diagnosis and management of cough (2015). Chin J Tuberc Respir Dis. 2016:39:321-39.

12. Asthma Workgroup of Chinese Society of Respiratory Diseases (CSRD), Chinese Medical Association. The Chinese national guidelines on diagnosis and management of asthma (2016). Chin J Tuberc Respir Dis. 2016:39:675-97.

13. Pulmonary Function Workgroup of Chinese Society of Respiratory Diseases (CSRD), Chinese Medical Association. The Chinese national guidelines of pulmonary function test (2014). Chin J Tuberc Respir Dis. 2014;37(8):566-71.

14. Payne DN, Adcock IM, Wilson NM, Oates T, Scallan M, Bush A. Relationship between exhaled nitric oxide and mucosal eosinophilic inflammation in children with difficult asthma, after treatment with oral prednisolone. Am J Respir Crit Care Med. 2001;164:1376-81.

15. Jatakanon A, Lim S, Kharitonov SA, Chung KF, Barnes PJ. Correlation between exhaled nitric oxide, sputum eosinophils, and methacholine responsiveness in patients with mild asthma. Thorax. 1998;53:91-5.

16. Silvestri M, Spallarossa D, Frangova Yourukova V, Battistini E, Fregonese B, Rossi GA. Orally exhaled nitric oxide levels are related to the degree of blood eosinophilia in atopic children with mild-intermittent asthma. Eur Respir J. 1999;13:321-6.

17. Ullmann N, Bossley CJ, Fleming L, Silvestri M, Bush A, Saqlani S. Blood eosinophil counts rarely reflect airway eosinophilia in children with severe asthma. Allergy. 2013;68:402-6.

18. Gutierrez V, Prieto L, Torres V, et al. Relationship between induced sputum cell counts and fluid-phase eosinophil cationic protein and clinical or physiologic profiles in mild asthma. Ann Allergy Asthma Immunol. 1999;82:559-65.

19. Berry MA, Shaw DE, Green RH, Brightling CE, Wardlaw AJ, Pavord ID. The use of exhaled nitric oxide concentration to identify eosinophilic airway inflammation: an observational study in adults with asthma. Clin Exp Allergy. 2005;35:1175-9.

20. Lex C, Ferreira F, Zacharasiewicz A, et al. Airway eosinophilia in children with severe asthma: predictive values of noninvasive tests. Am Respir Crit Care Med. 2006:174:1286-91.

21. Schleich FN, Seidel L, Sele J, et al. Exhaled nitric oxide thresholds associated with a sputum eosinophil count 3\% in a cohort of unselected patients with asthma. Thorax. 2010;65:1039-44.

22. Korevaar DA, Westerhof GA, Wang J, et al. Diagnostic accuracy of minimally invasive markers for detection of airway eosinophilia in asthma: a systematic review and meta-analysis. Lancet Respir Med. 2015;3:290-300.

23. Bjermer L, Alving K, Diamant Z, et al. Current evidence and future research needs for FeNO measurement in respiratory diseases. Respir Med. 2014;108:830-41.

24. Sørensen LT, Toft BG, Rygaard J, et al. Effect of smoking, smoking cessation, and nicotine patch on wound dimension, vitamin C, and systemic markers of collagen metabolism. Surgery. 2010;148:982-90.

25. Freedman DS, Flanders WD, Barboriak JJ, Malarcher AM, Gates L. Cigarette smoking and leukocyte subpopulations in men. Ann Epidemiol. 1996;6:299-306.

26. Hou L, Lloyd-Jones DM, Ning H, et al. White blood cell count in young adulthood and coronary artery calcification in early middle age: coronary artery risk development in young adults (CARDIA) study. Eur J Epidemiol. 2013;28:735-42.

27. Sunyer J, Springer G, Jamieson B, et al. Effects of asthma on cell components in peripheral blood among smokers and non-smokers. Clin Exp Allergy. 2003;33:1500-5.

28. Telenga ED, Kerstjens HAM, Ten Hacken NHT, Postma DS, van den Berge M. Inflammation and corticosteroid responsiveness in ex-, current and never-smoking asthmatics. BMC Pulm Med. 2013;13:58.

29. Thomson NC, Chaudhuri R, Heaney LG, et al. Clinical outcomes and inflammatory biomarkers in current smokers and exsmokers with severe asthma. J Allergy Clin Immunol. 2013;131:1008-16.

30. Giovannelli J, Chérot-Kornobis N, Hulo S, et al. Both exhaled nitric oxide and blood eosinophil count were associated with mild allergic asthma only in non-smokers. Clin Exp Allergy. 2016;46:543-54. 